\title{
Energetic and economic analysis of the Electric Vehicles charge impacts on public parking lots
}

\author{
E. Alcover, B. Mas, V. Martínez-Moll, J.L. Rosselló, M. Roca and V. Canals \\ Department of Industrial Engineering and Construction \\ University of the Balearic Islands, Palma, Ctra. Valldemossa km 7.5, Campus UIB, \\ Balearic Islands E-07122, Spain \\ Phone/Fax number:+34 971 173426, e-mail: enric.alcover@uib.cat, v.canals@uib.es
}

\begin{abstract}
.
This work addresses the energy and economic impact of electric vehicle (EV) charging services in public car parks; related to the evolution of EV penetration in the Spanish car fleet in the next 5 years. All this in the framework of the transition towards green and smart mobility. A statistical methodology has been developed to plan the number of EV charge stations to deploy in public car parks, estimate their energy demand (in minute intervals), and finally calculate the monthly energy costs. Specifically, this methodology is used to analyse the evolution of operating costs; as well as the investment costs due to the EV charging services of a public car park located in a centric area of Palma de Mallorca, Spain.
\end{abstract}

\section{Key words.}

Pluggable electric vehicle, Mobility, Monte Carlo method, Energy economics, Artificial intelligence

\section{Introduction}

In order to limit and reduce long-term increase in average planet temperature, it is necessary to reduce the emissions of $\mathrm{CO}_{2}$ and other greenhouse gases (GHG) emitted by human activities. The goal of $\mathrm{CO}_{2}$ emissions reduction of $70 \%$ by 2050 compared to 2015 [1], requires the transformation of the global energy system. Specially the passenger and freight transport sector, that represents the $25 \%$ of world energy consumption [2]. For that, many countries are looking toward a substitution of the traditional combustion vehicles for greener alternatives. Being the most extended alternatives the plug-in hybrid vehicles (PHEV) and pure battery electric vehicles (BEV) that seems to be more respectful with the environment and presents lower operational costs. Nonetheless, this energetic model transformation requires of the planification of a charging infrastructure that can satisfy the increasing energy demand of the EV charging [3].

Although the electric mobility and the deployment of its charging infrastructure has been widely studied [4], no studies have focused to the plan the charge facilities in existent public car parks from real mobility patterns, which is essential to enable a correct public investment plan; in order to drive penetration of electric mobility [5].

The methodology proposed in this work consist on a Monte-Carlo statistical method that obtains EV occupancy of a car park minute by minute EV; all this, from the data related to the individual car billing (time of entry and exit, amount, duration) of the reference year (2018). The developed tool determines the number of charge stations and park spaces that must be set in a car park in order to satisfy the $99 \%$ or the $99.6 \%$ of EV charge attempts, in a given period. Next, the energy demand associated to the EVs charging is estimated with the methodology taking into account multiple factors such as: the penetration of $\mathrm{EV}$ in the interest area car fleet, the charge characteristics of the different EV models, and the parking patterns of a given car park. Finally, the energy and the operational costs will be determined.

Finally, the proposed methodology is applied to analyze the operational costs and the investment need to support the EV charge service in "Via Roma"; a public car park located in a centric area of Palma de Mallorca (Balearic Islands), Spain.

\section{Evolution of $\mathrm{EV}$ penetration}

In order to forecast the EV energy demand, plan the charging infrastructures needed and evaluate its energetic and economic impact; it is essential to know at least the percentage of $\mathrm{EV}$ penetration in the area of interest. However, no official Spanish national or regional forecasts are available on this topic. Faced with this situation we proceeded to forecast the implantation of the $\mathrm{EV}$ in the passenger car fleet at the Balearic Islands for the period (2019-2023). The state of the electric mobility market in the Balearic Islands is very similar to the average of Spain, then the Spanish sales evolution can be extrapolated to the local behaviour. For this, it has been 
used two main input data sources, how are the historical data of EVs monthly sales at national level and historical data of the passenger car fleet at the Balearic Islands, obtained from the Direccion Generat de Trafico (DGT) [6]. The EV sales time series at national level for the period from 01/01/2014 to 31/12/2019, has been obtained from the Spanish Association of Automobile Manufacturers and Trucks (ANFAC) [7]. Based on the Spanish historic monthly electric vehicle sales time series, a statistical model of the Auto Regressive Integrated Moving Average (ARIMA) family was implemented in MATLAB to forecast monthly electric vehicle sales through December 2023. Specifically, the implemented model is a Seasonal Auto Regressive Integrated Moving Average (SARIMA) [8], as in (1), in order to incorporate the seasonality effect of the vehicle sales throughout the year in the model. Once the time series has been analysed and its basic components identified. The parameters of the model have been set with $\phi_{0}=0$, the number of differences is set to $d=1$ in order to make the time series stationary, a non-seasonal moving average term order is set to $\mathrm{q}=1$, and finally a seasonal term of period is set to 12 (months) and unit order of the Seasonal Moving Average is set to $(\mathrm{SMA}=1)$, period corresponding to one year.

$$
\mathrm{Yt}=\left(\phi_{0}+\sum_{\mathrm{i}=1}^{\mathrm{p}} \phi_{i} \Delta^{\mathrm{d}} \mathrm{Y}_{\mathrm{t}-1}\right)+\left(\mathrm{Y}_{\mathrm{t}}-\Delta^{\mathrm{d}} \mathrm{Y}_{\mathrm{t}}\right)+\left(\varepsilon_{t}-\sum_{\mathrm{i}=1}^{\mathrm{q}} \theta_{i} \varepsilon_{\mathrm{t}-1}\right)
$$

Finally, based on the estimation of the EV market share and the mean values of the volume of the Balearic Islands' passenger car fleet, the number of annual car registrations and car drops, all of them obtained from the DGT website [6], the penetration of the electric vehicle in the car fleet of the Balearic Islands has been estimated for the period 2019-2023 (Table I).

Table I. - Forecasted EV penetration in the car fleet for the period (2019-2023), at the Balearic Islands.

\begin{tabular}{|c|c|c|}
\hline Year & $\begin{array}{c}\text { EV in circulation at the } \\
\text { Balearic Islands }\end{array}$ & $\begin{array}{c}\text { EV penetration in the } \\
\text { car fleet }\end{array}$ \\
\hline 2019 & 1.817 & $0,28 \%$ \\
\hline 2020 & 3.117 & $0,47 \%$ \\
\hline 2021 & 5.331 & $0,81 \%$ \\
\hline 2022 & 9.100 & $1,38 \%$ \\
\hline 2023 & 15.516 & $2,35 \%$ \\
\hline
\end{tabular}

The models that make up the EV fleet used for the Monte Carlo simulations has been obtained from the analysis of annual sales at the Spanish level obtained from IDEAUTO [9] in the period (2014-2019). Finally, the percentages of each model obtained at the state level have been extrapolated to the local fleet to be simulated. This fleet is made up of the 12 best-selling EV models, 6 PHEV and 6 $\mathrm{BEV}$; Always maintaining the real ratio between BEV and PHEV.

\section{Methodology}

The proposed methodology focuses on analyze AC slow and semi-fast EV charge [2,3-22kW] in public car parking operated in rotation regime, for small EV penetration levels [0-2,35\%] as today. The methodology has been implemented as a tool in MATLAB $®$. In turn, this tool is made up of 7 sub-modules that implement specific parts of the developed methodology and it incorporates a Monte Carlo algorithm at its core, which will perform a minuteby-minute simulation of the parking lot (inputs and outputs of electric vehicles, energy demand) for a time series of ten or more repetitions of the reference year (2018). Each of the sub-modules is presented below:

\section{Analysis and Modeling of Parking Occupancy}

This sub-module is in charge of adjusting a statistical distribution of the two main patterns that defines the behaviour of the parking from the historical billing data obtained from the individual tickets of the reference year. The first pattern is related with the parking periods distribution, that has been obtained from the histogram of parking durations, constructed for 10 minute intervals in a range of [0-5000] minutes. The shape of the obtained histogram follows a continuous distribution Weibull's distribution We $(\mathrm{x} ; \lambda, \mathrm{k})$, as (2).

$$
\mathrm{f}(\mathrm{x} ; \lambda ; \mathrm{k})=\left\{\begin{array}{ll}
\frac{\mathrm{k}}{\lambda}\left(\frac{x}{\lambda}\right)^{k-1} e^{-\left(\frac{x}{\lambda}\right)^{k}} & x \geq 0 \\
0 & x<0
\end{array}\right\}
$$

There are two parameters that define the Weibull distribution: the shape parameter $\mathrm{k}>0$ and the scale parameter of the distribution $\lambda>0$. These parameters are being determined using the least squares method. The second parking pattern is related with the hourly mean occupancy that is obtained from the mean number of vehicles that start and end their parking each hour throughout a certain period.

\section{Load demand curve generator}

This sub-module is in charge to generate the charging curves of the EV fleet, from the power grid point of view. The vehicles that conform this virtual fleet are loaded from an external file (.csv) that has a EV model in each column and its information: useful battery power, absolute penetration percentage of the model, the time until full charge, and the nominal charging power.

To generate the demand curve of each EV entering on the parking, the methodology emulates the demand associated with battery charge, using a two-step function. A first one at constant nominal power $\left(P_{\text {car }}\left(t_{i}\right)=P_{\text {car_nom }} / 60\right)$ and the second one at variable power, that decreases exponentially $\left(P_{\text {car }}\left(t_{i}\right)=P_{\text {car } \_ \text {nom }} \mathrm{e}^{\text {at }} / 60\right)$; which starts when the remaining energy until full charge is less than the energy that would be charged at nominal power in one hour, the method adjusts the parameter "a" of the negative exponential function of the nominal power by numerical integration.

\section{EV Occupancy Generator}

This sub-module determines the EV occupancy from the hourly mean occupation of the analysed parking and the EV penetration in the local car fleet, introducing a stochastic factor in order to reproduce the real behaviour of the parking energy demand. For that, the sub-module generates as many random numbers uniformly distributes $\mathrm{U}(0,1)$ as vehicles expected to enter into the parking at a 
certain hour interval, if the random generated number is lower than the EV penetration, the vehicle is assumed to be electric. Then, for each EV that enters into the garage, three more random numbers are generated. The first is an uniformly random number $\mathrm{U}(1,60)$ that determines the EV entering minute along the hour interval. Then, another uniformly random number $\mathrm{U}(0,1)$ will determine the model of the EV. Finally, one random number that follows the Weibull distribution " $t_{e s t}=W_{e}(\lambda, k, U(0,1))$ " is generated in order to fix the time duration of the parking. Finally, this sub-module will determine the EV park space requirements to cover the percentiles $99 \%$ and $99,6 \%$, for all the evaluation period, in order to set the optimum number of EV charge stations and park space needed at the parking.

\section{Hourly base demand generator}

The power demand of a public car park is essentially related to the lighting and ventilation systems. The lighting depends on the parking surface and its location (opening periods to the public), meanwhile the ventilation system depends on the parking's surface/volume, because it is used to evacuate the combustion gases of vehicles in circulation, in addition to renewing the interior air.

The methodology used to evaluate the hourly mean base electric demand consists of accounting, from the electric bills, the energy consumed for the different pricing periods throughout a year. This task is performed by the sub-module loading an external file (.csv) with the monthly billing of the studied parking, incorporating for each one a row with all the information of the historical invoices of the electrical supply for an access toll 3.0A $\left(\mathrm{P}_{\text {cont }} \geq 15 \mathrm{~kW} @ 400 \mathrm{~V}_{\mathrm{AC}}\right)$, where the details of the bill are found.

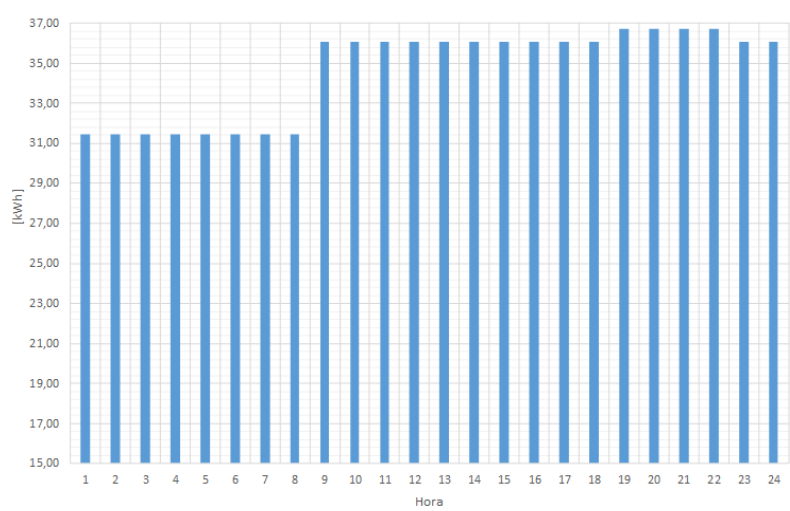

Fig. 1. Average hourly consume of the analysed public parking.

\section{Real occupation and energy demand generator}

Once the number of EV charging points has been determined, this sub-module is in charge to determine the real demand of the parking with the limitation of the number of charge stations of the facility stablished. This is done generating two one-dimensional matrixes, with as many elements as minutes in the evaluation period. The first one is used to store the real minute by minute EV occupancy, and is going to increase its value by one between the entering minute and its exit if the number of parked EV is less than the already fixed EV charging lots. The second matrix is going to increase its value with the instantaneous power demand of the EV charging. Finally, this module merges the different energy demands (EV charging demand and hourly base demand) for is further analyse.

\section{Demand Integrator}

This sub-module is in charge to integrate the energy consumption in periods of 15 minutes (quarter-hourly) and hourly. This information is very relevant to evaluate the energy billing for the economic analysis due to the maximeter term (integrated in the power term), on the energy bill, that is related to the quarter-hourly demand.

\section{Energy billing}

This last sub-module determines the monthly energy bill [10] of a given public car park. The energy billing of the vast majority of the public car parks, that operates in rotation, have contracted a $3.0 \mathrm{~A}$ access toll. In order to calculate the energy bill, this system uses always hourly discrimination in the three periods: P1 (rush), P2 (flat) and P3 (valley), with different energy price for each period. Also, there are several additional terms that contribute to the final energy price.

The first term is the power term, that represent the cost of the reserve of availability of the hired power in the electrical system. Although the hired power can be different for each of the three billing periods, it must always be at least $15 \mathrm{~kW}$. Then the power term is obtained multiplying the hired power $[\mathrm{kW}]$ by the cost at each period $\left[€ / \mathrm{kW}_{\text {year }}\right]$ for each period, as (3).

Term $_{\text {pow }}=\left(\right.$ Pow $_{P 1} \cdot \cos t_{P 1}+$ Pow $_{P 2} \cdot \cos t_{P 2}+$ Pow $\left._{P 3} \cdot \cos t_{P 3}\right) \frac{\# \text { days }}{365}$

The final cost of the power term is, in fact, determined by the maximeter that is responsible of measuring the quarter-hourly consume of the installation. Then, if the power is greater than $105 \%$ of the hired power a penalty corresponding to twice the difference between the recorded value and the value corresponding to $105 \%$ of the contracted power. Then, the active energy that is calculated by multiplying the energy demand hourly integrated $[\mathrm{kWh}]$ at each billing period for the price of electricity $[€ / \mathrm{kWh}]$ in such period. Then, the energy tax is calculated after adding the previous terms. This tax [\%] is applied before the VAT is charged, and its amount is determined by the governmental authorities. It is calculated by (4).

$$
\operatorname{Tax}_{\text {electr }}=\left(\text { Cost }_{\text {electricity }}\right) \cdot E_{-} \operatorname{tax}[\%]
$$



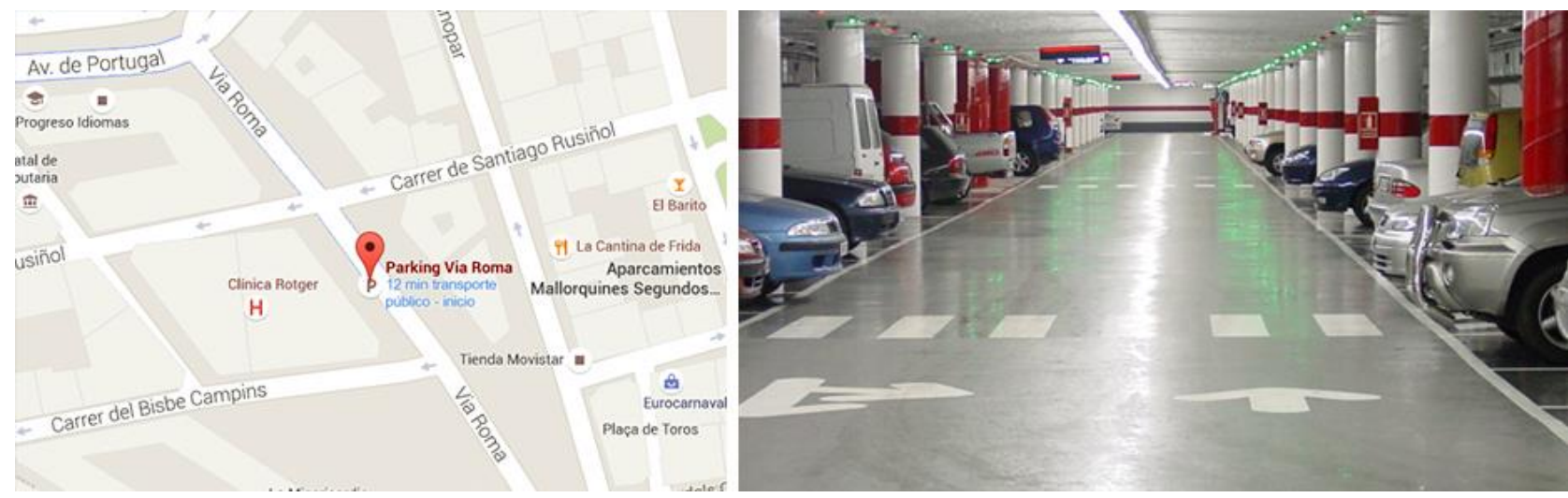

Fig.2. Location of the public parking of Via Roma object of the present study, at Palma of Majorca.

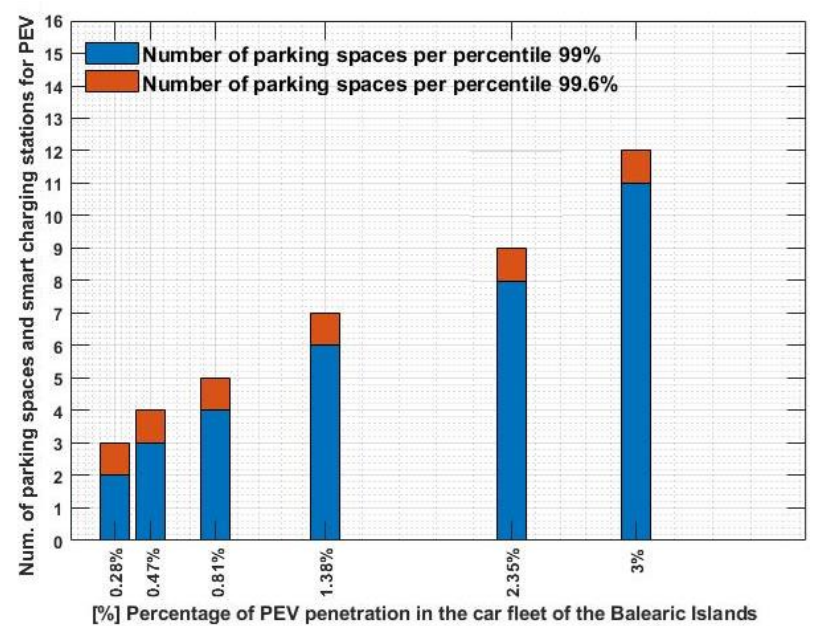

Fig.3. Forecast of the evolution of the needed parking spaces and intelligent charging stations for EV. In blue the parking spaces needed to cover $99 \%$ of EV parking attempts, and in red for covering the $99,6 \%$.

Finally, the rental of measuring equipment and its maintenance is also billed. The cost is fixed by the electricity distributor and is proportional to the number of days in the billing period.

\section{Results}

The developed methodology has been applied to the "Via Roma" public parking lot located in a prime location of the city of Palma of Majorca (Fig. 2); specifically, on the way of one of the direct entrances of Palma of Majorca city centre. Currently, this parking has 766 parking lots, of which 472 are exploited in rotation regime with an average volume of 484.604 rotations per year. It is open $24 \mathrm{~h}$ of the day, the 365 days of the year.

This public parking lot has contracted a 3.0A access toll with $125 \mathrm{~kW}$ contracted power for each of the three billing periods (P1 | P2 | P3) and it has an annual average energy consumption of 303.420,97 kWh/year and currently has 5 parking spaces dedicated exclusively to electric vehicles, equipped with intelligent charge stations (SAVE).

\section{Load infrastructure planning}

The planning of EV charge infrastructure deployment is the preliminary phase to any energy and / or economic analysis that is to be carried out, with the proposed methodology. For this reason, the number of smart charging stations and electric vehicle parking spaces needed to cover the percentiles 99 and 99,6 percentiles of the expected number of EV parking attempts has been estimated for the next 5 years (2019-2023); according to the EV penetration forecast previously for the Balearic Islands car fleet. It should be noted that EV penetration values have been additionally included beyond 2023 using data from an IEA study [11] which states that to achieve the goals of the scenario increase the average temperature of the planet no higher at $2^{\circ} \mathrm{C}[12]$, it would be necessary to replace $10 \%$ of light vehicles (conventional car fleet) for electric vehicles by 2030 .

At the same time, it can be seen in Fig. 3, how the number of recharging infrastructures $\left(\mathrm{N}_{\text {infra_Ev }}\right)$ needed to support the electric vehicle grows linearly with the penetration percentage of the electric vehicle $\left(\mathrm{p}_{\mathrm{EV}}\right)$. Being the relationship between them (5):

$$
N_{\text {inf } r a_{-} E V}=2,4997 \cdot p_{E V}+1,7709 \mid \quad R^{2}=0,9937
$$

Once the requirements for $\mathrm{EV}$ charge infrastructure have been assessed, in the next 5 years, the requirements for new parking spaces and EV charge stations that will need to be installed annually is obtained. Since, this car park there are already $5 \mathrm{EV}$ parking spaces reserved and equipped with intelligent charge stations, type SAVE, model INGEREV Garage GW332 (Ingeteam Corporación, S.A.), supporting slow and semi-fast charging modes provide broad support for the main charging modes that the major electric vehicle manufacturers incorporate.

\section{Energy analysis}

The proposed methodology is going to determine the total amount of energy demand of the parking minute by minute, summing up the base demand and the demand of the EV charging, that depends on the EV penetration level. To subsequently integrate them into quarterly and hourly periods to determine the electricity consumption in 
the different billing periods of a 3.0A access toll, described above, and which will be used for further analysis. Then, the mean annual demand for each of the three billing periods will be calculated.

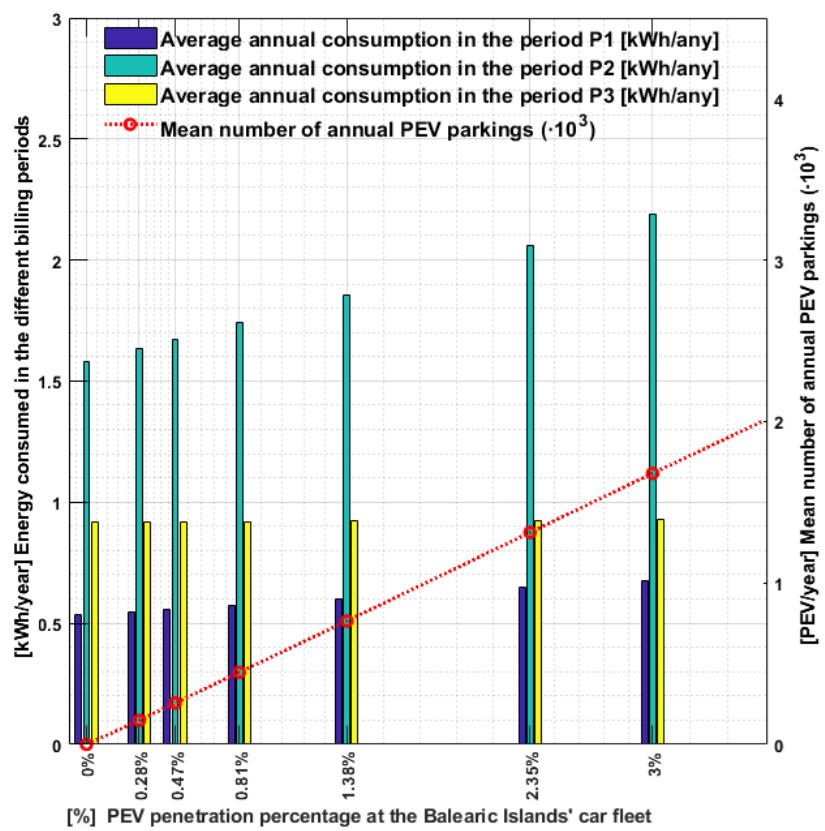

Fig.4. Evolution of energy demand by billing periods related with the EV percentage of penetration.

As can be seen in the Fig. 4, the increase in average annual demand will be concentrated in the turnover period (plan) P2 (8-18h and 22-24h) and to a lesser extent in the period (peak) P1 (18-22h). While in the period (valley) P3 $(0-8 \mathrm{~h})$ the increase in demand will be virtually negligible, due to the low occupancy number and the little amount of rotations in this period.

Comparing the energy demand with the reference year's one, it can be seen how the total energy demand (P1 + P2 + P3) will be increased by $30,73 \%$ in just 5 years. While the energy demand of period P1 will be increased by $34,60 \%$, that of period P2 will be increased by $46,69 \%$, and that of period P3 will only be increased by an imperceptible $1 \%$.

At the same time, if we analyse the increase of the global demand $(\mathrm{P} 1+\mathrm{P} 2+\mathrm{P} 3)$ annual based on the evolution of the percentage of penetration of the electric vehicle $p_{E V}$ over the next 5 years; we can see how for this car park the demand will grow linearly with the penetration of the EV following the following expression (6).

$$
\Delta \text { Pot }_{\text {Global }}=13,142 \cdot p_{E V}[\%] \quad R^{2}=0,999
$$

\section{Economic analysis}

The determination of the cost of the energy bill associated with the deployment of EV charging infrastructures for different levels of EV penetration; it is essential to analyse the increments in energy costs compared to the reference year (2018). In later sections they will be used to address the costs associated with the deployment of recharging infrastructure in order to assess the operating costs of the energy recharging service.

To address the analysis of the evolution of energy costs associated with the increase in energy demand in the car park; we will start from the energy costs of the reference year (2018), which essentially include the operating costs of the car park as they are lighting, ventilation, etc. The results obtained show under any doubt how even small penetrations of the EV in the car fleet will involve very significant increases in the amount of the energy bill. For example, in just five years, 2023, the energy bill of the car park will be increased by $24,78 \%$ with only $2,35 \%$ penetration of the electric vehicle.

Therefore, the increases in energy costs are mainly linked to the energy term; while the power term will remain constant. This is due to the power demanded quarterly will never exceed that contracted, and therefore the maximum of the installation will not change the amount of the monthly power term.

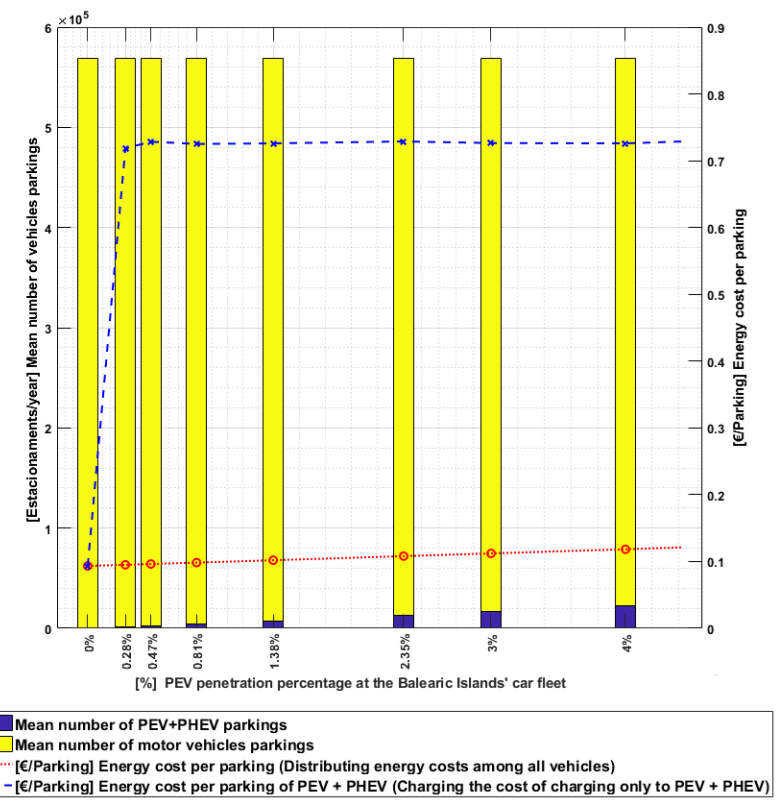

Fig.5. Evolution of the associated energy costs for vehicle parking related with the $\mathrm{EV}$ percentage of penetration.

Finally, it will be analysed the evolution of energy costs for vehicle parking (electric and combustion) as a function of the percentage of penetration of the EV. Fig. 5 shows the increase in energy costs linked to the electric vehicle parking recharging service as a function of the EV penetration percentage. Which have been calculated using the following equation (7):

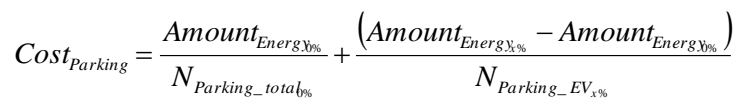

As can be seen, the annual energy cost per EV parking for a given percentage of $\mathrm{EV}$ penetration includes the base energy costs of the parking lot (ventilation, lighting...) in 
addition to the energy extra cost associated with the recharging service divided by the annual average of electric vehicle parking lots. The results obtained show that for the next 5 years, the energy part of the bill prices will increase from the $0.10 €$ to the $0.13 €$ per parking, considerable percentage increase. Where the evolution costs for parking, red line in Fig.5, will grow linearly in this parking, following the expression (8):

$$
\operatorname{Cost}_{\left(\frac{\text { Energy }}{\text { Parking }}\right)}=0,014 p_{E V}+0,0969\left[\frac{€}{\text { Parking }}\right] \mid R^{2}=0,995
$$

While the energy costs associated with each electric vehicle parking lot will increase from the actual $0.10 €$ to around the $1,20 €$, to keep the cost stable until it grows again from the $3 \%$ of $\mathrm{EV}$ penetration in the car fleet, of the Balearic Islands.

Besides the cost of the energy consumption of the parking, it is important to make an estimation of the economic aspects associated with the adaptation of the facilities in order to achieve the energy charging service. Then, the investment costs to deploy the new charge stations to provide this service, including material and labour force, amounts to $15.851,63 €$; the investment detail is summarized in Table II. As it can be appreciated, the case study there has already 5 charge stations (SAVE) installed, then, the investment for reaching the 8 desired charging point it is smaller than if we did not have any infrastructure. The total energetic costs caused by the EV energy demand are also obtained, with a total increase on the electricity bill of $29.728,22 €$ in the next 5 years.

Table II. - EV charge service infrastructure investment, in the period (2019-2023).

\begin{tabular}{|l|c|c|}
\hline Concept & Quantity & Amount [€] \\
\hline $\begin{array}{l}\text { EV Charging equipment + IP } \\
\text { communications }\end{array}$ & 3 & $13.698,38$ \\
\hline Electrical installations & --- & $6.067,50$ \\
\hline Engineering and legalization & 1 & $1.529,25$ \\
\hline Parking space signalling & 3 & 624 \\
\hline \multicolumn{2}{|r|}{ Total: } & $\mathbf{1 5 . 8 5 1 , 6 3 €}$ \\
\hline
\end{tabular}

\section{Conclusions}

This work has presented a complete methodology to forecast the impacts of the increase of $\mathrm{EV}$ penetration on parking that offers recharging services. In turn, this tool is useful to any parking operated in rotation regime which wants to provide EV charging services, and has available the parking bills data.

As seen in this study the impacts on the energy consume related with EV charging service is not negligible, with an energy demand increased by $30,73 \%$ with only a $2,35 \%$ of EV penetration on car fleet. It should also be noted that the energy demand is concentrated along two billing periods of the day (P1 and P2), while in the night (P3) the energy demand increase is imperceptible. This fact suggests the possibility of balancing the increase on the energy demand through PV facilities near the parking lots, decreasing, in such way, thus helping to decongest the electricity grid.

Given the actual scenario, the increase on the energy demand will be traduced to an important increase on the electric billing of the analysed facility. In addition, an important investment has to be done to adapt the public parking to the new needs of the private cars customer's, although this investment can be done in different phases, until reaching the forecasted amount in the next 5 years.

\section{Acknowledgement}

This work was supported in part by the Spanish Ministry of Economic Affairs and Digital Transformation (MINECO) and the EU with Regional European Development Funds under Grant TEC2017-84877-R.

\section{References}

[1] IRENA and IEA, "Perspectives for the Energy Transition: Investment Needs for a Low-Carbon Energy Transition," 2017.

[2] DOE, EIA, and Office of Energy Analysis, International Energy Outlook 2016, With Projections to 2040. Energy Dept.; Energy Information Administration; Office of Energy Analysis, 2016.

[3] M. Hemphill and N. South, "Electricity Distribution System Planning for an Increasing Penetration of PlugIn Electric Vehicles in New South Wales," in 2012 22nd Australasian Universities Power Engineering Conference (AUPEC), 2012, pp. 1-6.

[4] C. F. Heuberger, P. K. Bains, and N. Mac Dowell, "The EV-olution of the power system: A spatio-temporal optimisation model to investigate the impact of electric vehicle deployment," Applied Energy, vol. 257, p. 113715, Jan. 2020, doi: 10.1016/j.apenergy.2019.113715.

[5] R. S. Levinson and T. H. West, "Impact of public electric vehicle charging infrastructure," Transportation Research Part D: Transport and Environment, vol. 64, pp. 158-177, Oct. 2018, doi: 10.1016/j.trd.2017.10.006. "Dirección General de Tráfico (DGT)." [Online]. Available: http://www.dgt.es/es/seguridadvial/estadisticas-e-indicadores/.

[7] "Asociación Española de Fabricantes de Automóviles y Camiones (ANFAC).” [Online]. Available: https://anfac.com/.

[8] T.-M. Choi, Y. Yu, and K.-F. Au, "A hybrid SARIMA wavelet transform method for sales forecasting," Decision Support Systems, vol. 51, no. 1, pp. 130-140, Apr. 2011, doi: 10.1016/j.dss.2010.12.002.

[9] "Instituto de Estudio de Automoción (IDEAUTO)." [Online]. Available: https://www.ideauto.com/.

[10] Ministerio de Industria Energía y Turismo, "Resolución de 23 de mayo de 2014, de la Dirección General de Política Energética y Minas, por la que se establece el contenido mínimo y el modelo de factura de electricidad.," Madrid, Spain, 2014.

[11] IEA - International Energy Agency, "Global EV Outlook 2019: Scaling up the transition to electric mobility," 2019 .

[12] UNFCCC Secretariat, "Synthesis report on the aggregate effect of the intended nationally determined contributions, FCCC/CP/2015/7," Paris, 2015. 